\title{
Characterization of the Potent, Selective Nrf2 Activator, 3-(Pyridin-3-Ylsulfonyl)-5-(Trifluoromethyl)-2H-Chromen-2-One, in Cellular and In Vivo Models of Pulmonary Oxidative Stress
}

\author{
John G. Yonchuk, Joseph P. Foley, Brian J. Bolognese, Gregory Logan, William E. Wixted, \\ Jen-Pyng Kou, Diana G. Chalupowicz, Heidi G. Feldser, Yolanda Sanchez, Hong Nie, \\ James F. Callahan, Jeffrey K. Kerns, and Patricia L. Podolin \\ Stress and Repair Discovery Performance Unit, Respiratory Therapeutic Area, GlaxoSmithKline, King of Prussia, Pennsylvania \\ Received May 17, 2017; accepted August 2, 2017
}

\begin{abstract}
Nuclear factor (erythroid-derived 2)-like 2 (Nrf2) is a key regulator of oxidative stress and cellular repair and can be activated through inhibition of its cytoplasmic repressor, Kelch-like ECHassociated protein 1 (Keap1). Several small molecule disrupters of the Nrf2-Keap1 complex have recently been tested and/or approved for human therapeutic use but lack either potency or selectivity. The main goal of our work was to develop a potent, selective activator of NRF2 as protection against oxidative stress. In human bronchial epithelial cells, our Nif2 activator, 3-(pyridin-3-ylsulfonyl)-5-(trifluoromethyl)-2H-chromen-2-one (PSTC), induced Nrf2 nuclear translocation, Nrf2-regulated gene expression, and downstream signaling events, including induction of $\mathrm{NAD}(\mathrm{P}) \mathrm{H}$ :quinone oxidoreductase 1 (NQO1) enzyme activity and heme oxygenase-1 protein expression, in an Nrf2dependent manner. As a marker of subsequent functional activity, PSTC restored oxidant (tert-butyl hydroperoxide)induced glutathione depletion. The compound's engagement
\end{abstract}

of the Nrf2 signaling pathway translated to an in vivo setting, with induction of Nrf2-regulated gene expression and NQO1 enzyme activity, as well as restoration of oxidant (ozone)-induced glutathione depletion, occurring in the lungs of PSTC-treated rodents. Under disease conditions, PSTC engaged its target, inducing the expression of Nrf2-regulated genes in human bronchial epithelial cells derived from patients with chronic obstructive pulmonary disease, as well as in the lungs of cigarette smoke-exposed mice. Subsequent to the latter, a dosedependent inhibition of cigarette smoke-induced pulmonary inflammation was observed. Finally, in contrast with bardoxolone methyl and sulforaphane, PSTC did not inhibit interleukin$1 \beta$-induced nuclear factor- $\kappa \mathrm{B}$ translocation or insulin-induced S6 phosphorylation in human cells, emphasizing the on-target activity of this compound. In summary, we characterize a potent, selective Nrf2 activator that offers protection against pulmonary oxidative stress in several cellular and in vivo models.

\section{Introduction}

Chronic obstructive pulmonary disease (COPD), the fourth leading cause of death worldwide, is defined by the Global Initiative for Chronic Obstructive Lung Disease as a common preventable disease characterized by persistent airflow limitation that is usually progressive, irreversible, and associated with an enhanced chronic inflammatory response in the airways and the lung to noxious particles or gases (http:// goldcopd.org). One key component of the pathophysiology of COPD is oxidative stress, including defective antioxidant defense, which can play a role in other underlying mechanisms of COPD such as activation of inflammatory genes, cellular senescence, autoimmunity, and corticosteroid resistance

https://doi.org/10.1124/jpet.117.241794.
(Barnes, 2014). Oxidative stress in the lung can be driven by insults such as cigarette smoke, air pollution, or other particulate matter in the air. It occurs when reactive oxygen species are produced in excess of cellular antioxidant defense mechanisms, resulting in damage to macromolecules such as proteins, lipids, or DNA.

The transcription factor nuclear factor (erythroid-derived 2)-like 2 (Nrf2) is a master regulator of antioxidant defense and phase II detoxifying enzymes. Nrf2 is a bZip transcription factor and member of the cap "n" collar family of regulatory proteins, which also includes nuclear factor (NF)-E2, Nrf1, Nrf3, Bach1, and Bach2 (Motohashi et al., 2002). Nrf2 has been shown to play a key role in the cellular response to oxidant stress by binding, as a heterodimer with small Maf proteins, antioxidant response elements in the promoters of phase II detoxifying enzymes (Itoh et al., 1997). Nrf2 is held in

ABBREVIATIONS: ALI, air-liquid interface; BAL, bronchial alveolar lavage; BEGM, bronchial epithelial cell growth medium; BTB, broad complex, tramtrack, bric-a-brac; CDDO-Me, bardoxolone methyl; Ct, threshold cycle; COPD, chronic obstructive pulmonary disease; DMA, dimethylacetoacetamide; DMF, dimethylfumarate; DMSO, dimethylsulfoxide; GCLM, glutamate-cysteine ligase modifier subunit; GSK, GlaxoSmithKline; HEK, human embryonic kidney; HO, heme oxygenase; IKK2, I $\mathrm{B}$ kinase 2; IL, interleukin; IVR, intervening region; KC, keratinocyte-derived cytokine (CXCL1); $\mathrm{m} / \mathrm{z}$, mass-to-charge ratio; mTOR, mechanistic target of rapamycin; NF, nuclear factor; NHBE, normal human bronchial epithelial; PBS, phosphate-buffered saline; PSTC, 3-(pyridin-3-ylsulfonyl)-5-(trifluoromethyl)-2H-chromen-2-one; SFN, sulforaphane; siRNA, small interfering RNA; tBHP, tert-butyl hydroperoxide; tBHQ, tert-butyl hydroquinone. 
a cytoplasmic complex with its repressor, Kelch-like ECHassociated protein 1 (Keap1), and Cullin3-dependent E3 ubiquitin ligase (Cul3). Under stress-free conditions, Keap1 maintains free Nrf2 at low levels by enabling Cul3 to ubiquitinate Nrf2, leading to its 26S proteosome-mediated degradation. However, Keap1 is repressed under oxidative stress conditions, resulting in activation and translocation of Nrf2 to the nucleus, thus triggering the antioxidant transcriptional response (Itoh et al., 1999). Keap1 is a 624-amino-acid protein containing three main domains: a broad complex, tramtrack, bric-a-brac (BTB) domain that facilitates homodimerization of Keap1 and the Keap1-Cul3 interaction, a cysteine-rich intervening region (IVR) domain, and a Kelch domain through which Keap1 binds Nrf2 (Baird and DinkovaKostova, 2011). The BTB and IVR domains of Keap1 have been shown to contain key reactive cysteine residues (Cys151, Cys273, and Cys288) that interact with electrophiles, resulting in activation of Nrf2 (Cleasby et al., 2014) and thus transcription of a host of antioxidant response genes.

Targeting the Nrf2 pathway through disruption of the Nrf2Keap1 complex, specifically via the modification of cysteine residues in the Keap1 BTB and IVR domains, has recently been the focus of drug development strategies for several diseases, including, but not limited to, cancer (Ross and Critchlow, 2014), chronic kidney disease (Rojas-Rivera et al., 2012), and multiple sclerosis (Phillips and Fox, 2013). The Nrf2 pathway also holds promise for COPD treatment, where oxidative stress plays a role in pathology and Nrf2 signaling has been found to be dysfunctional (Goven et al., 2008; Yamada et al., 2016). There are currently several clinical assets, such as dimethylfumarate (DMF) (also known as BG-12 or Tecfidera; Biogen, Cambridge, MA) and bardoxolone methyl (CDDO-Me), that target the Nrf2 pathway. DMF is approved for use in patients with multiple sclerosis, although interestingly, research now suggests that this drug may be acting through mechanisms in addition to Nrf2, such as the hydroxycarboxylic acid receptor 2 (Chen et al., 2014). Currently, CDDO-Me is in a phase 3 trial in patients with connective tissue disease-associated pulmonary arterial hypertension and a phase $2 / 3$ trial is planned in patients with chronic kidney disease caused by Alport syndrome. In a phase 3 trial for chronic kidney disease in patients with type 2 diabetes, CDDO-Me was terminated due to adverse cardiovascular side effects (de Zeeuw et al., 2013), which could be attributable to off-target effects on endothelin signaling (Chin et al., 2014). These findings highlight the need to develop more potent and selective Nrf2 activators for use in diseases in which Nrf2 plays a role, such as COPD. Herein we describe the development of a small molecule activator of Nrf2, 3-(pyridin-3-ylsulfonyl)-5-(trifluoromethyl)$2 \mathrm{H}$-chromen-2-one (PSTC), and the characterization of its potency, efficacy, and selectivity in cellular and in vivo models of pulmonary oxidative stress.

\section{Materials and Methods}

Compounds and Reagents. PSTC, CDDO-Me, and the $\mathrm{I} \kappa \mathrm{B}$ kinase 2 (IKK2) inhibitor 5-(4-fluorophenyl)-2-ureidothiophene-3carboxamide (Podolin et al., 2005) were synthesized by the Stress and Repair Discovery Performance Unit within the Respiratory Therapeutic Area at GlaxoSmithKline (GSK) (King of Prussia, PA). Sulforaphane (SFN) was purchased from Toronto Research Chemicals
(Toronto, ON, Canada), and DMF was purchased from Vitas-M Laboratory (Champaign, IL).

Cells and Cell Culture. Normal human bronchial epithelial (NHBE) cells were purchased and maintained in complete bronchial epithelial cell growth medium (BEGM) according to the manufacturer's recommendations (Lonza, Walkersville, MD) and were used up to passage 5. BEAS-2B human epithelial cells were obtained from American Type Culture Collection (Manassas, VA) and were cultured in complete BEGM up to passage 10 for experimentation. Human embryonic kidney (HEK)-293 cells were purchased from American Type Culture Collection and were routinely cultured in Dulbecco's modified Eagle's medium containing high glucose, glutamine, and sodium pyruvate with $10 \%$ heat-inactivated fetal bovine serum purchased from Life Technologies (Grand Island, NY) and were used at passages 2-5 for experimentation. Epithelial cells derived from bronchial brushings of subjects with COPD (provided by Dr. Steven Kelsen, Center for Inflammation, Translational, and Clinical Lung Research Laboratory, Temple University, Philadelphia, PA; protocol number 11764 approved by the institutional review board at Temple University) were grown and maintained in a 1:1 mixture of bronchial epithelial cell basal medium (Lonza) and Dulbecco's modified Eagle's medium (Life Technologies) with all-trans retinoic acid (Sigma-Aldrich, St. Louis, MO) and the following additives from a BEGM SingleQuot kit (Lonza): human recombinant epidermal growth factor, hydrocortisone, bovine pituitary extract, epinephrine, transferrin, insulin, triiodothyronine, gentamicin and amphotericin. Cells from subjects used in this study were grown at the air-liquid interface (ALI) at passage 2 on Transwell 24-well permeable membrane (Corning Inc., Corning, NY) submerged for the first 3 days, during which time the culture medium was changed on day 1 and every other day thereafter. The ALI was created once the cells reached $100 \%$ confluence, by removing the apical medium and restricting the culture feeding to the basolateral compartment of the plates. The culture medium was changed every other day until the cells were differentiated at approximately 28 days. The human biologic samples were sourced ethically and their research use was in accord with the terms of the informed consent. Studies were performed in accordance with the Declaration of Helsinki.

Transfections. NHBE cells were plated at $5 \times 10^{4}$ cells per well in 24-well plates and were transfected the following day with $25 \mathrm{nM}$ nontargeting or Nrf2 small interfering RNA (siRNA) (Dharmacon/Thermo Scientific, Waltham, MA) for 48 hours according to the supplier's general transfection protocol. The wells were aspirated and the cells were treated with vehicle [dimethylsulfoxide (DMSO); Sigma-Aldrich] or compound in complete bronchial epithelial cell basal media without antibiotics for 24 hours at $37^{\circ} \mathrm{C}$ and $5 \% \mathrm{CO}_{2}$. The wells were aspirated and the cells were lysed with Complete Lysis-M Buffer (Roche, Indianapolis, IN) on ice for protein analysis or lysis buffer from the Illustra RNA Kit (GE Healthcare Life Sciences, Pittsburgh, PA) for mRNA determination.

Western Blotting. Whole-cell lysate protein concentrations were determined with a colorimetric assay detection kit (BioRad, Hercules, CA) and were subjected to immunoblot analysis. Equal amounts of denatured protein lysates were separated on a $12.5 \%$ Tris-HCl Criterion precast gel and were transferred to a nitrocellulose membrane (BioRad). The membrane was blocked with 5\% (w/v) ECL Prime blocking agent (GE Healthcare Life Sciences, Piscataway, NJ) in phosphate-buffered saline (PBS) without $\mathrm{Ca}^{+2}$ and $\mathrm{Mg}^{+2}$ containing $0.1 \%(\mathrm{v} / \mathrm{v})$ Tween 20 (Sigma-Aldrich). The blot was exposed to rabbit polyclonal anti-human heme oxygenase (HO)-1 (diluted 1:2000; Enzo Life Sciences, Farmingdale, NY) overnight at $4^{\circ} \mathrm{C}$. Two PBS/0.1\% Tween wash steps were performed followed by the addition of an antirabbit IgG horseradish peroxidase-conjugated secondary antibody (diluted 1:5000; Cell Signaling Technology, Danvers, MA). HO-1 protein levels were detected with ECL detection reagent (GE Healthcare Life Sciences) and the autoradiograph was developed with a processor (Konica, Tokyo, Japan). Protein loading was assessed by stripping the membrane and reprobing for $\beta$-actin using a goat polyclonal IgG anti-actin horseradish peroxidase-conjugated 
antibody (diluted 1:1000; Santa Cruz Biotechnology, Santa Cruz, CA). Quantification of HO-1 and $\beta$-actin signals was performed using a BioRad Gel Doc EZ Imager and BioRad Image Laboratory Software (version 3.0).

Analysis of Gene Expression. For human samples, RNA was isolated using the Illustra RNA Kit (GE Healthcare Life Sciences) and the TaqMan assay was performed using probe/primer pairs to detect human NQO1, HO-1, glutamate-cysteine ligase modifier subunit (GCLM), and thioredoxin reductase 1 (TXNRD1) (Applied Biosystems, Foster City, CA). Data were normalized to $18 \mathrm{~S}$ levels using the $\Delta \Delta$ threshold cycle $(\mathrm{Ct})$ method. For rodent samples, RNA was isolated using TRIzol reagent (Life Technologies). Five-hundred nanograms of RNA from each sample was reverse transcribed in a $20-\mu l$ reaction using QuantiTect reverse transcription (Qiagen, Germantown, MD) according to recommended conditions. Real-time polymerase chain reaction was performed on the ABI ViiA7 real-time polymerase chain reaction system (Applied Biosystems) using $18 \mathrm{~S}$ as the internal control. The cDNA was amplified with probe/primer pairs for mouse or rat Nqo1, Ho-1, sulfiredoxin 1 (Srxn1), and Txnrd1 (obtained from TaqMan gene expression assays; Applied Biosystems) using universal master mix (Applied Biosystems). An identical Ct was applied for each gene of interest. The comparative $\mathrm{Ct}(\Delta \Delta \mathrm{Ct})$ relative quantification method was used to calculate the relative mRNA levels of target genes as described in the Applied Biosystems Chemistry Guide.

For NanoString gene expression profiling, a set of Nrf2-dependent genes selected from the literature was used to generate a code set (NanoString Technologies, Seattle, WA) including four normalization controls (ACTB, GAPDH, GUSB, RPL13A). One-hundred nanograms of purified RNA (RNAspin Mini RNA Isolation Kit; GE Healthcare Life Sciences) was used for RNA quantification according to the manufacturer's instructions. Data were analyzed using NanoString nSolver Analysis Software (version 1.1).

Nrf2 Nuclear Translocation. NHBE cells were cultured on plastic as described above until they were $>80 \%$ confluent. On the day of the assay, vehicle (DMSO), PSTC, or tert-butyl hydroquinone (tBHQ) (Crescent Chemical Co., Islandia, NY) was added for 6 hours and then nuclear extracts were generated using the protocol included with the TransAm Nrf2 kit (Active Motif, Carlsbad, CA). Protein concentrations were determined with a colorimetric assay detection kit (BioRad). Nuclear samples were then assayed using the TransAm Nrf2 kit. For siRNA studies, cells were transfected as described above for 48 hours followed by 6 hours of treatment with vehicle or compounds. Cells were then processed as described above.

NQO1 Enzyme Activity Assay. NQO1-specific enzyme activity was measured using an assay adapted from Prochaska and Santamaria (1988). For human samples, NHBE cells were cultured in complete BEGM medium, treated with $25 \mathrm{nM}$ Nrf2 or nontargeting siRNA for 48 hours where indicated, and then exposed to vehicle (DMSO) or compounds for 48 hours. The medium was removed and crude cellular lysates were made using cell lysis buffer (Cell Signaling Technology) containing a protease inhibitor tablet (EDTA-free complete mini protease inhibitor; Roche Life Science, Indianapolis, IN). An aliquot was removed for assaying protein content via a colorimetric assay detection kit (BioRad). NQO1 activity was determined by adding $40 \mu \mathrm{l}$ sample to $200 \mu \mathrm{l}$ NQO1 activity cocktail [25 mM Tris, $\mathrm{pH} 7.4$, $0.067 \%$ bovine serum albumin, $0.01 \%$ Tween-20, $5 \mu \mathrm{M}$ flavin adenine dinucleotide, $1 \mathrm{mM}$ glucose-6-phosphate, $2 \mathrm{U} / \mathrm{ml}$ glucose-6-phosphate dehydrogenase, $3 \mu \mathrm{M}$ NADP, $0.83 \mu \mathrm{M}$ menadione, and $0.3 \mathrm{mg} / \mathrm{ml}$ 3-(4,5-dimethylthiazol-2-yl)-2,5-diphenyltetrazolium bromide] in duplicate with $10 \mu \mathrm{l}$ of $20 \mu \mathrm{M}$ dicoumarol (Sigma-Aldrich) or water. Absorbance was then measured at $570 \mathrm{~nm}$ for 30 minutes. For rodent samples, lung tissue was homogenized in buffer $(50 \mathrm{mM}$ Tris- $\mathrm{HCl}$, $\mathrm{pH} 7.5,15 \mathrm{mM} \mathrm{NaCl}, 1 \% \mathrm{NP}-40,100 \mathrm{mM} \mathrm{NaF}$, and $50 \mathrm{mM} \beta-$ glycerophosphate) containing one protease inhibitor tablet (Roche Life Science) per $10 \mathrm{ml}$ homogenization buffer. Homogenate was incubated on ice for 15 minutes and then centrifuged at $1000 \mathrm{~g}$ for 15 minutes at $4^{\circ} \mathrm{C}$. The entire sample was remixed and transferred to a clean $1.5-\mathrm{ml}$ Eppendorf tube for centrifugation at $13,000 \mathrm{~g}$ for 5 minutes at $4^{\circ} \mathrm{C}$.
Clear cytosolic supernatant was collected and used for determination of protein content (BioRad) and NQO1 activity. For the latter, $10 \mu \mathrm{l}$ of $20 \mu \mathrm{M}$ dicoumarol (Sigma-Aldrich) or water was added to $40 \mu \mathrm{l}$ tissue lysates and then $200 \mu \mathrm{l} \mathrm{NQO} 1$ activity cocktail was added. Absorbance was measured at $570 \mathrm{~nm}$ for 30 minutes.

Glutathione Assay. For human samples, NHBE cells at passage 4 were treated with vehicle (DMSO) or compounds for 18 hours followed by addition of tert-butyl hydroperoxide (tBHP) or $\mathrm{N}$-acetylcysteine (Sigma-Aldrich) for 4 hours under the indicated conditions. Crude cell lysates were generated and assayed for glutathione content according to the manufacturer's protocol using 5\% sulfosalicylic acid (DetectX Glutathione Fluorescent Detection Kit; Arbor Assays, Ann Arbor, MI). For rat samples, glutathione content was determined following the manufacturer's instructions (Cayman Chemical, Ann Arbor, MI). One-hundred milligrams of lung tissue was normalized to $0.10 \mathrm{mg} / \mathrm{ml}$ with $1 \times 2$-( $N$-morpholino)ethanesulfonic acid buffer and homogenized using a gentleMACS Dissociator (Miltenyi Biotec Inc., Auburn, CA). Sample were centrifuged at $228 \mathrm{~g}$ for 10 minutes at $4^{\circ} \mathrm{C}$ and then clarified at $13,000 \mathrm{~g}$ for 5 minutes at $4^{\circ} \mathrm{C}$. Samples were deproteinated at a 1:1 ratio with metaphosporic acid (500 $\mu \mathrm{l}$ sample plus $500 \mu \mathrm{l}$ metaphosporic acid) and vortexed immediately. Fifty microliters of $4 \mathrm{M}$ triethanolamine (Sigma-Aldrich) was then added to increase the $\mathrm{pH}$, and samples were diluted at 1:5 and/or 1:10 for glutathione assay.

NF-кB Nuclear Translocation. BEAS-2B cells were plated and treated with vehicle (DMSO) or compound for 30 minutes and then stimulated with $2 \mathrm{ng} / \mathrm{ml}$ interleukin (IL)- $1 \beta$ for 30 minutes. Cells were then fixed with $4 \%$ paraformaldehyde and NF- $\kappa \mathrm{B}$ levels were determined using the NF- $\kappa \mathrm{B}$ high content screening assay (Thermo Scientific) and imaging on a PerkinElmer Operetta system PerkinElmer (Waltham, MA). NF- $\kappa$ B levels were analyzed using a Harmony software (version 3.1) nuclear translocation script and are reported as the percent inhibition of the mean nuclear fraction of vehicle-treated controls. The $\mathrm{IC}_{50}$ for each compound was determined using GraphPad Prism software (version 5.0; GraphPad Software Inc., La Jolla, CA) via nonlinear regression, using a sigmoidal doseresponse (variable slope) and constraining the top to $<100$, the bottom to $>0$, and the Hill slope to $<2.0$.

Mechanistic Target of Rapamycin Assay. HEK-293 cells were incubated for 1.5 hours with vehicle (DMSO), $20 \mathrm{nM}$ rapamycin (SigmaAldrich), or Nrf2 activators at the indicated concentrations, followed by the addition of $100 \mathrm{nM}$ insulin (Sigma-Aldrich) for 30 minutes. Cells were lysed in $0.2 \mathrm{ml}$ lysis buffer and phospho-S6 ribosomal protein (Ser235/236) and total S6 ribosomal protein were analyzed by ELISA (Cell Signaling) per the manufacturer's instructions. Values are expressed as the ratio of phospho-S6 optical density/total S6 optical density, normalized as the percentage of the average ratio with insulin.

Animals. C57BL/6J mice (25-30 g; Jackson Laboratory, Bar Harbor, ME) and Han Wistar rats (290-370 g; Charles River Laboratories, Wilmington, MA) were maintained on a 12-hour/12-hour light/dark cycle and were provided Purina LabDiet 5001 (St. Louis, MO) and water ad libitum. All studies were conducted in accordance with the Guide for the Care and Use of Laboratory Animals as adopted and promulgated by the U.S. National Institutes of Health and were reviewed and approved by the GSK Policy on the Care, Welfare, and Treatment of Laboratory Animals.

PSTC-Induced Gene Expression and NQO1 Activity, In Vivo. To assess Nrf2-regulated mRNA expression and NQO1 enzyme activity after dosing of PSTC, seven to eight mice or five rats per treatment group received a single oral administration of vehicle [0.9\% DMSO, 7\% dimethylacetoacetamide (DMA; Sigma-Aldrich), 10\% Cremophor El (Sigma-Aldrich), and $82.1 \%$ water] or PSTC at the indicated doses. Six and 48 hours after dosing, animals were euthanized (as described below) and lung tissue was collected for the analysis of gene expression and NQO1 enzyme activity, respectively, as described above. For gene expression analysis, 100-200 mg lung tissue was placed in $5 \mathrm{ml}$ RNAlater (Thermo Scientific), the tissue was promptly cut into small 5 -cm pieces, and the samples were stored at $-80^{\circ} \mathrm{C}$. For measurement of NQO1 activity, lung tissue was snap frozen and stored at $-80^{\circ} \mathrm{C}$. 
Cigarette Smoke Exposure. C57BL/6J mice received nose-only exposure to $4 \%$ cigarette smoke from $3 \mathrm{R} 4 \mathrm{~F}$ cigarettes (Reference Cigarette Program, College of Agriculture, University of Kentucky, Lexington, KY), for 2 hours per day for 3 days. Mainstream smoke was generated by a Baumgartner-Jaeger CSM 2070i smoking machine $(\mathrm{CH}$ Technologies Inc., Westwood, NJ), which contains a circular head that holds 30 cigarettes and performs $1 \mathrm{rpm}$. A 4\% concentration of smoke was produced via a 2 -second, 35 -ml puff of smoke once per minute from each cigarette; 1 liter of the resulting smoke was mixed with 24 liters of air and delivered to the exposure tower. During exposure to smoke or air (sham controls), mice were maintained in restraining tubes containing stainless-steel nose cone inserts. Where indicated, mice received once-daily oral administration of vehicle $(0.9 \%$ DMSO, $7 \%$ DMA, $10 \%$ Cremophor El, and $82.1 \%$ water) or compound during the 3 days of smoke exposure as well as 24 hours before the initial smoke exposure. Six or 24 hours after the final smoke exposure on day 3, mice were anesthetized with isoflurane and then euthanized via cardiac exsanguination followed by cervical dislocation. Bronchoalveolar lavage (BAL) fluid was collected for cell counts, or lung tissue was collected and 1) stored in RNAlater at $-80^{\circ} \mathrm{C}$ for analysis of gene expression or 2) snap frozen and stored at $-80^{\circ} \mathrm{C}$ for analysis of cytokine levels.

BAL Fluid Collection and Cell Counting. For mice, the trachea was cannulated with a 3-inch piece of PE90 tubing (BD, Franklin Lakes, $\mathrm{NJ}$ ) fitted over a blunt 21-gauge needle, to which a three-way stopcock was attached (Baxter Healthcare, Deerfield, IL). Four 1-ml aliquots of ice-cold PBS were injected and removed sequentially through the tubing. After centrifugation at $140 \mathrm{~g}$ for 2 minutes, cell pellets from the four aliquots were combined. For rats, the trachea was cannulated with a gavage needle attached to a 5 -ml syringe. One 3-ml aliquot of icecold PBS was injected and removed through the gavage needle, and the resulting BAL fluid was centrifuged at $140 \mathrm{~g}$ for 2 minutes. Total cells were counted using a hemocytometer. Differential cell analysis was performed on cytospins using Wright-Giemsa stain.

Cytokine Analysis. Lung tissue was weighed, suspended in $1 \mathrm{ml}$ PBS/g tissue, and homogenized using a gentleMACS Octo Dissociator with M tubes (Miltenyi Biotec Inc., Auburn, CA). The tissue homogenate was then centrifuged at $2500 \mathrm{~g}$ for 10 minutes, and the resulting supernatant was centrifuged at $400 \mathrm{~g}$ for 10 minutes. Keratinocytederived cytokine (KC; CXCL1) levels were measured using a mouse ELISA kit purchased from R\&D Systems (Minneapolis, MN). Assays were performed according to the manufacturer's instructions.

Ozone Exposure. Han Wistar rats were exposed to ozone generated by an Oxycycler ozonator (Biospherix Inc., Lacona, NY), in which compressed air and oxygen were passed through the ozonator and flowed into a plexiglass chamber containing the animals. Twenty-four hours prior to ozone injury, rats received a single oral administration of vehicle $(0.9 \%$ DMSO, $7 \%$ DMA, $10 \%$ Cremophor El, and $82.1 \%$ water) or compound. Rats were exposed to $1 \mathrm{ppm}$ ozone for a 3-hour period. Ozone concentrations, humidity, and $\mathrm{CO}_{2}$ within the chamber were constantly monitored using Oxycycler Watview software and an independent ozone monitor (Teledyne Advanced Pollution Instrumentation Inc., Thousand Oaks, CA). The rats were euthanized 15 minutes after injury by intraperitoneal administration of $1 \mathrm{ml}$ Fatal Plus (Vortech Pharmaceuticals, Dearborn, MI). BAL fluid was collected for cell counts, or lung tissue was collected, snap frozen, and stored at $-80^{\circ} \mathrm{C}$ for analysis of glutathione content.

Quantitative Analysis of PSTC and the Corresponding Hydroxy Acid in Blood. The blood samples were immediately added to acidified acetonitrile, $0.1 \%$ formic acid, containing $75 \mathrm{ng} / \mathrm{ml}$ propranolol as the internal standard for mass spectrometry analysis, in a 1:4 ratio (i.e., $50 \mu \mathrm{l}$ blood into $200 \mu \mathrm{l}$ acetonitrile/formic acid/ propranolol) and stored in a $-80^{\circ} \mathrm{C}$ freezer until analysis. For analysis of drug concentration, the blood samples were thawed, vortexed, and centrifuged $\left(1207 \mathrm{~g}, 4^{\circ} \mathrm{C}, 10\right.$ minutes). A $50-\mu \mathrm{l}$ aliquot of the supernatant was vortexed with $50 \mu \mathrm{l}$ water for injection onto the mass spectrometer. Analysis of the samples was performed using liquid chromatography/ tandem mass spectrometric detection. Twenty-microliter injections were made onto the liquid chromatography/tandem mass spectrometric system using Agilent 1100 Series binary pumps (Agilent Technologies, Santa Clara, CA) and a CTC PAL Autosampler (CTC Analytics, Zwingen, Switzerland). The mobile phase consisted of a gradient that transitioned linearly from $95 \%$ aqueous $10 \mathrm{mM}$ ammonium formate, $\mathrm{pH} 3$, and $5 \%$ acetonitrile to $66 \%$ acetonitrile over 2 minutes ( $500 \mu \mathrm{l} / \mathrm{min}$ flow rate) and then to $95 \%$ acetonitrile over an additional minute, was held at those conditions for 0.5 minutes, and then reconditioned back to initial conditions for an additional 2.5 minutes. An Agilent SB-C18 4.6- $\times$ 50-mm analytical column was used to retain the analytes. The eluent flowed into a Sciex API 4000 triple quadrupole mass spectrometer (Applied Biosystems) using negative-ion turbo ion spray multiple-reaction monitoring for the first 3.35 minutes and then switching to positive-ion turbo ion spray multiple-reaction monitoring for 2.65 minutes. PSTC was characterized by the transition of the mass-to-charge ratio $(\mathrm{m} / z) 356.1$ parent $(\mathrm{M}+\mathrm{H})^{+}$ion to its $\mathrm{m} / z$ 213.1 product ion, generated at optimized collision energy. The internal standard, propranolol, was characterized by the transition of the $\mathrm{m} / \mathrm{z}$ 260.2 parent $(\mathrm{M}+\mathrm{H})^{+}$ion to its $\mathrm{m} / z 116.1$ product ion, generated at optimized collision energy. The corresponding hydroxy acid of PSTC was characterized by the transition of the $m / z 372.0(\mathrm{M}-\mathrm{H})^{-}$ion to its $\mathrm{m} / z 328.2$ ion.

Statistical Analysis. Data are presented as the mean \pm S.E.M. Statistical significance was determined using a one-way analysis of variance with a Dunnett or Bonferroni post-test. $P$ values of $\leq 0.05$ were considered significant.

\section{Results}

Structure and Characteristics of PSTC. A series of sulfonyl coumarins were originally identified by screening the GSK collection for activators of Nrf2. An exemplar from this series, PSTC (Fig. 1A), is a potent disrupter $\left(\mathrm{pIC}_{50}=7.1\right)$ of the interaction between Cul3 and Keap1, as measured by a Cul3-Keap1 fluorescence resonance energy transfer assay (Cleasby et al., 2014) designed to identify inhibitors of this proteinprotein interaction. Further evaluation of PSTC in BEAS-2B cells (Davies et al., 2016) showed that it was a potent $\left(\mathrm{pEC}_{50}=7.7\right)$ inducer of NQO1-specific enzyme activity. PSTC was prepared by heating 2-hydroxy-6-(trifluoromethyl)benzaldehyde with 2-(pyridin-3-ylsulfonyl)acetic acid in acetic anhydride. Although PSTC was stable under acidic conditions, under basic conditions it was converted to a salt of the hydroxy acid (Fig. 1B) with a mixture containing each compound observed at physiologic $\mathrm{pH}$. The in vitro profiling of either PSTC or the corresponding hydroxy acid gave similar results in the Cul3-Keap1 fluorescence resonance energy transfer assay $\left(\mathrm{pIC}_{50}=7.1 / 6.9\right)$ and the BEAS-2B cell assay $\left(\mathrm{pEC}_{50}=7.7 / 7.0\right)$ supporting the assertion that the two compounds exist as an equilibrium mixture at physiologic $\mathrm{pH}$. When tested in a selectivity panel containing 50 enzymes, receptors, ion channels, and phenotypic cell health screens, the two compounds exhibited activity against cannabinoid receptor type $2\left(\mathrm{pXC}_{50}=5\right.$ for each compound).<smiles>O=c1oc2cccc(C(F)(F)F)c2cc1S(=O)(=O)c1cccnc1</smiles><smiles></smiles>

Fig. 1. Structure of PSTC (A) and the corresponding hydroxy acid (B). 


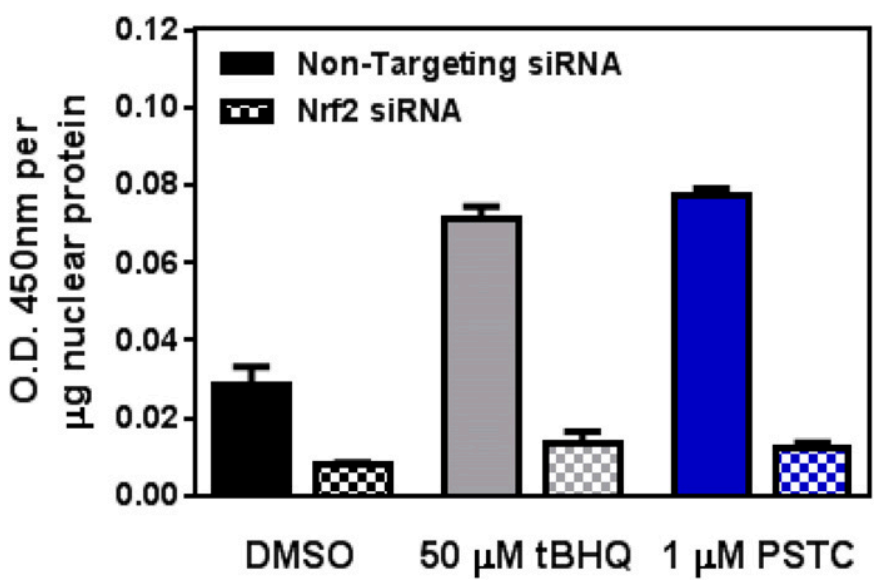

Fig. 2. The PSTC-induced increase in nuclear Nrf2 protein levels is attenuated by knockdown with Nrf2 siRNA. NHBE cells were transfected with a nontargeting or Nrf2 siRNA for 48 hours and then treated with vehicle (DMSO), PSTC, or tBHQ for 6 hours. Subsequently, Nrf2 protein levels were measured in nuclear fractions. Data are expressed as the mean of three independent experiments \pm S.E.M. O.D., optical density.

Comparator Nrf2 activators, CDDO-Me, SFN, and DMF, exhibited $\mathrm{pEC}_{50}$ values of 8.4, 5.8 and 5.6, respectively, in the induction of NQO1-specific enzyme activity in BEAS-2B cells. In our experiments, compounds were used at concentrations at the upper plateau of their respective concentration-response curves to achieve maximum pharmacologic effect. In the selectivity panel, CDDO-Me exhibited activity $\left(\mathrm{pXC}_{50} \geq 5\right.$ ) against the serotonin $2 \mathrm{~A}$ receptor (6.6), serotonin $2 \mathrm{C}$ receptor (5.9), adrenergic $\alpha 1 b$ receptor (6.1), adrenergic $\alpha 2 \mathrm{c}$ receptor (5.4), dopamine 1 receptor (5.7), dopamine 2 receptor (5.8), histamine 1 receptor (6.6), vasopressin 1a receptor (6.7), phosphodiesterase 4B (5.6), L-type calcium channel (CaV1.2) (5.3), aurora B (STK12) (5.4), muscarinic 1 receptor (5.6), muscarinic 2 receptor (5.7), neurokinin 1 receptor (6.5), $\mu$ opioid receptor (5.8), $\kappa$ opioid receptor (5.7), cell health-mitochondrial integrity (5.9), cell health-membrane permeability (5.9), and cell health-nucleus size (6.1); SFN exhibited activity against potassium voltage-gated channel subfamily KQT member 1/potassium voltage-gated channel subfamily E regulatory subunit 1 (6.1); and DMF exhibited no activity $\left(\mathrm{pXC}_{50}<5\right)$.

PSTC Induces Nrf2 Nuclear Translocation in NHBE Cells via an Nrf2-Dependent Mechanism. To evaluate the ability of PSTC to repress Keap1 and thus activate Nrf2, we monitored Nrf2 nuclear translocation in NHBE cells. Cells were transfected with a nontargeting or Nrf2 siRNA for 48 hours and were then exposed to PSTC $(1 \mu \mathrm{M})$ or a comparator Nrf2 activator, tBHQ $(50 \mu \mathrm{M})$, for 6 hours. PSTC induced an increase in Nrf2 nuclear translocation and this increase was abolished by pretreatment with Nrf2 siRNA but not nontargeting siRNA (Fig. 2). Similar results were seen in tBHQ-treated cells. In separate studies, treatment of NHBE cells with PSTC $(10 \mu \mathrm{M})$ for 6 or 24 hours did not induce
A

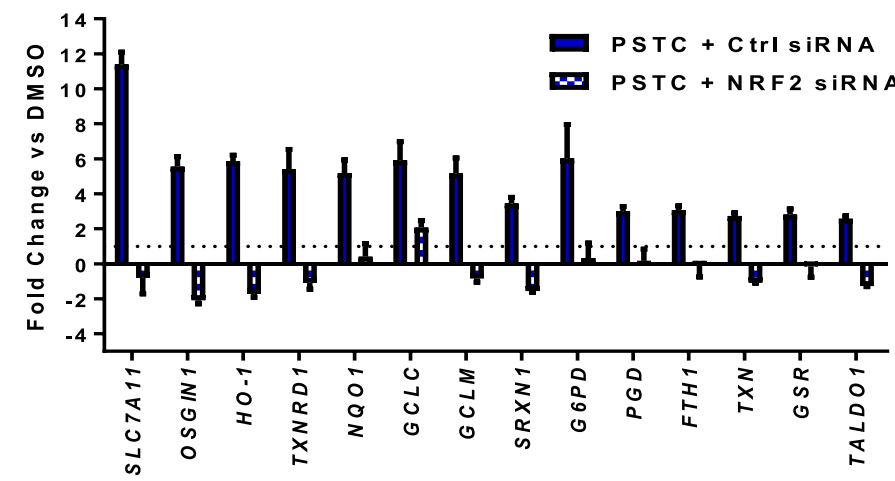

B
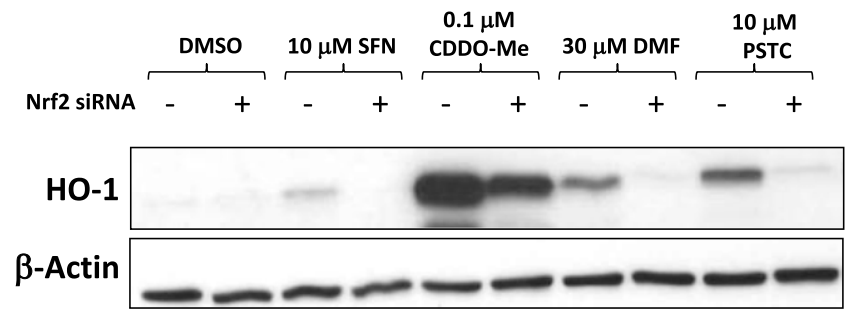

C

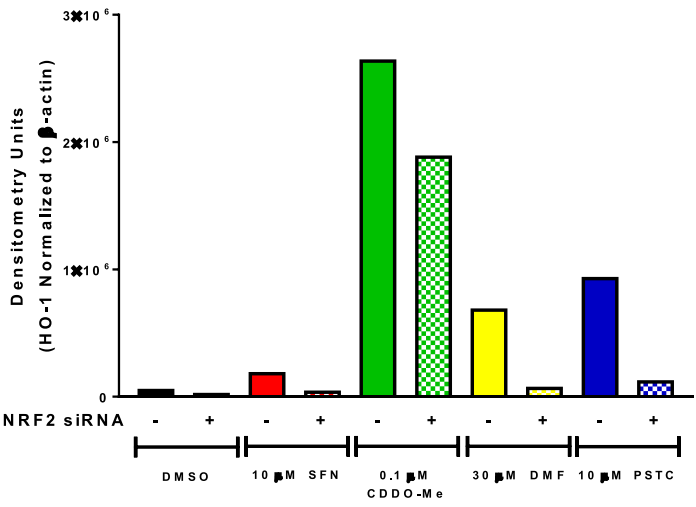

D

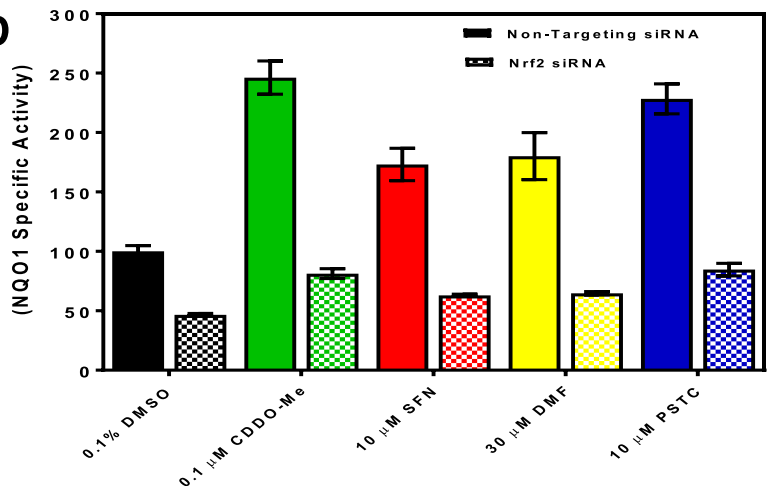

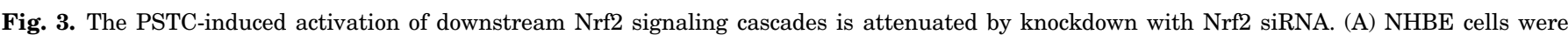

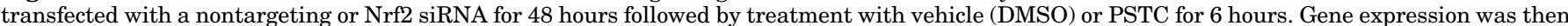

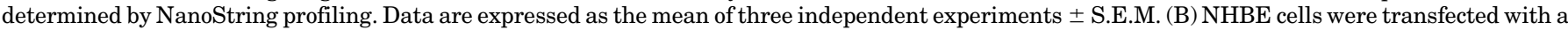

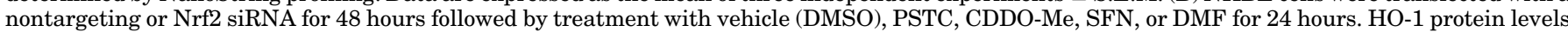

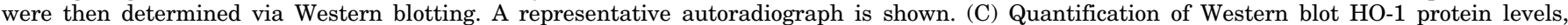

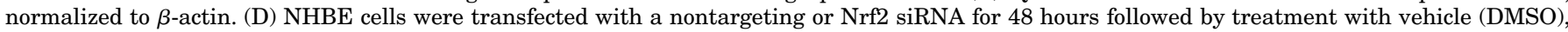

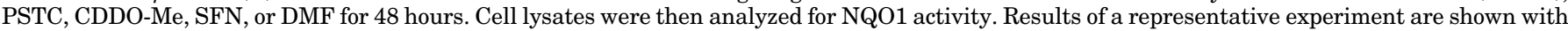
data expressed as the mean \pm S.E.M. 


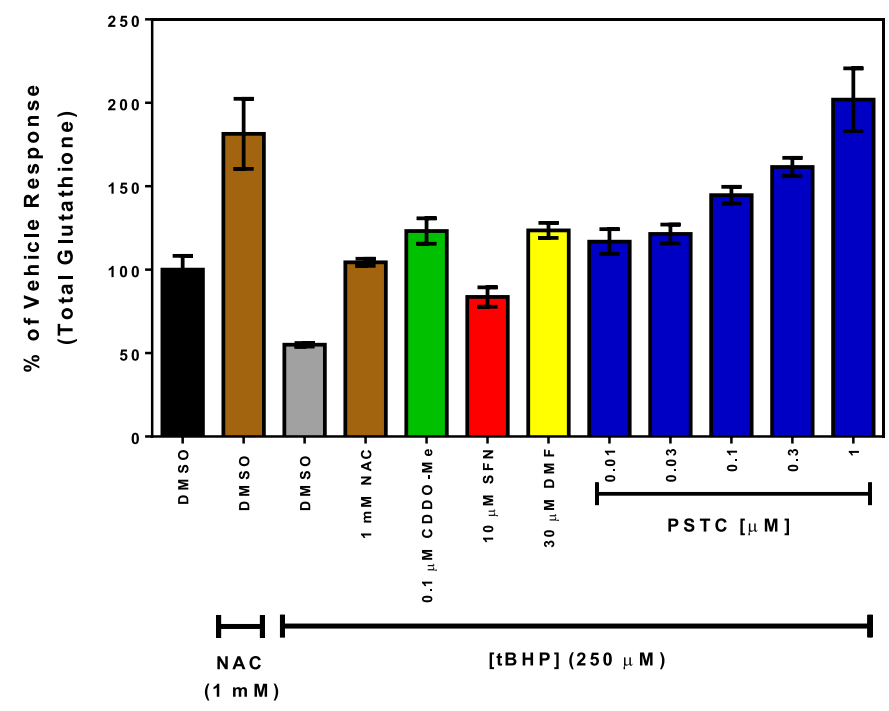

Fig. 4. PSTC protects NHBE cells from tBHP-induced total glutathione depletion. NHBE cells were pretreated with vehicle (DMSO), PSTC, NAC, CDDO-Me, SFN, or DMF for 18 hours before the addition of $1 \mathrm{mM}$ NAC or $250 \mu \mathrm{M}$ tBHP for 4 hours to the indicated conditions. Cell lysates were then analyzed for total glutathione content. Results of a representative experiment are shown with data expressed as the mean \pm S.E.M. NAC, $N$-acetylcysteine.

significant changes in NRF2 gene expression (data not shown), suggesting that the Nrf2 nuclear translocation induced by PSTC is not a result of increased Nrf2 synthesis. Collectively, these data show that PSTC disrupts the Nrf2-Keap1 complex, thereby inducing nuclear translocation of Nrf2, and they confirm the specificity of the assay for Nrf2.

Nrf2-Regulated Phase II Enzymes Are Induced by PSTC via an Nrf2-Dependent Mechanism. We next analyzed whether PSTC-induced inhibition of Keap1, and subsequent nuclear translocation of Nrf2, would lead to downstream induction of Nrf2-dependent genes and proteins. Treatment of cells with $10 \mu \mathrm{M}$ PSTC for 6 hours increased expression of multiple Nrf2-dependent genes, including components of the glutathione synthesis/utilization pathway (GCLM, GCLC, GSR), quinone detoxification (NQO1), NADPH production $(G 6 P D, P G D)$, and iron sequestration pathways (HO-1, FTH1) (Fig. 3A). Upregulation of these genes was abolished upon pretreatment of cells with siRNA targeting Nrf2. In addition, HO-1 protein expression was increased after 24 hours (Fig. 3, B and C). This result was similar to those obtained with the Nrf2 activators CDDO-Me, SFN, and DMF. When cells were first transfected with Nrf2 siRNA for 48 hours prior to treatment with these compounds, this increased expression was diminished. Treatment of cells with $10 \mu \mathrm{M}$ PSTC for 48 hours also increased NQO1 enzyme activity in an Nrf2-dependent manner (Fig. 3D). This NQO1 response profile was similar for the three other Nrf2 activators: CDDO-Me, SFN, and DMF. Taken together, these results demonstrate engagement of Nrf2-dependent signaling pathways in cells treated with PSTC.

Activation of the Nrf2 Signaling Cascade by PSTC Protects NHBE Cells from tBHP-Induced Glutathione Depletion. To determine whether the activation of the Nrf2dependent cell machinery by PSTC would provide efficacy in a cellular model of oxidative stress, we employed tBHP-induced glutathione depletion in NHBE cells. Cells were pretreated for 18 hours with the indicated concentrations of PSTC or comparator Nrf2 activators CDDO-Me, SFN, or DMF and were then exposed to $250 \mu \mathrm{M}$ tBHP for 4 hours. Exposure of vehicle (DMSO)-treated NHBE cells to the antioxidant $N$-acetylcysteine or the oxidant tBHP alone caused upregulation and depletion, respectively, of total glutathione levels, whereas pretreatment with PSTC prior to tBHP exposure protected cells from glutathione depletion in a concentrationdependent manner (Fig. 4). Similarly, CDDO-Me, SFN, and DMF protected NHBE cells against glutathione depletion in this model.

PSTC Does Not Inhibit the Activation of NF- $\mathrm{B}$ in BEAS-2B Cells or Mechanistic Target of RapamycinDependent S6 Phosphorylation in HEK-293 Cells. Previous reports have established diverse effects of CDDO$\mathrm{Me}$, including its inhibition of the NF- $\kappa \mathrm{B}$ signaling pathway via direct interaction with IKK2 (Ahmad et al., 2006), as well as inhibition of the mechanistic target of rapamycin (mTOR) (Deeb et al., 2007). To address the specificity of PSTC, we designed an assay to measure IL- $\beta$-induced nuclear translocation of NF- $\kappa \mathrm{B}$ in BEAS-2B cells. In these experiments, cells were pretreated with the indicated concentrations of PSTC, CDDO-Me, SFN, DMF, or the IKK2 inhibitor 5-(4-fluorophenyl)-2-ureidothiophene-3-carboxamide for 30 minutes and were then stimulated with IL- $1 \beta$ for 30 minutes. In this assay, both CDDO-Me and SFN showed a concentrationdependent inhibition of $\mathrm{NF}-\kappa \mathrm{B}$ nuclear translocation, with a $\mathrm{pIC}_{50}$ of 5.7 for each, compared with a $\mathrm{pIC}_{50}$ of 6.1 exhibited by
A

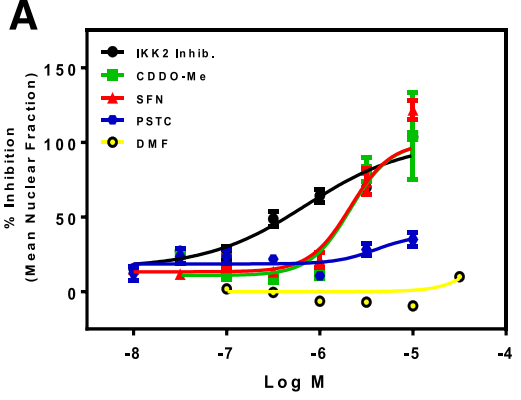

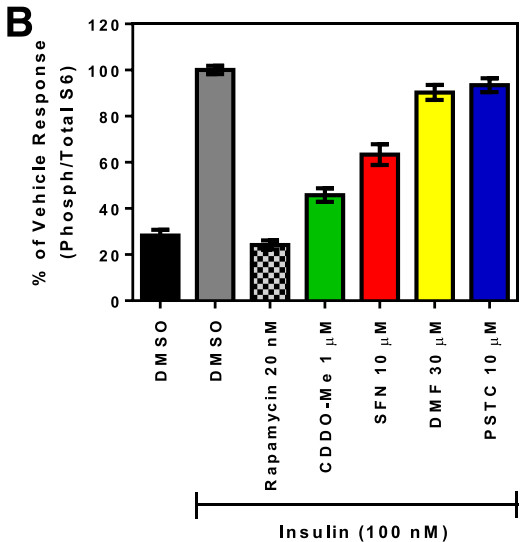

Fig. 5. PSTC is more selective than other Nrf2 activators. (A) BEAS-2B cells were treated with vehicle (DMSO), PSTC, IKK-2 inhibitor, CDDO-Me, SFN, or DMF at the indicated concentrations for 30 minutes, stimulated with IL- $1 \beta$ for an additional 30 minutes to activate the NF- $\kappa \mathrm{B}$ pathway, and then assayed for $\mathrm{NF}-\kappa \mathrm{B}$ nuclear translocation. Results of a representative experiment are shown with data expressed as the mean \pm S.E.M. LogIC $_{50}$ values were determined using GraphPad Prism software (version 5.0) with a sigmoidal dose-response (variable slope) and are reported in the Results. (B) HEK cells were treated with vehicle (DMSO), PSTC, rapamycin, CDDO-Me, SFN, or DMF for 1.5 hours before the addition of $100 \mathrm{nM}$ insulin for 30 minutes according to the indicated conditions. Cell lysates were then analyzed for phosphorylated and total S6 protein content. Results of a representative experiment are shown with data expressed as the mean \pm S.E.M. 


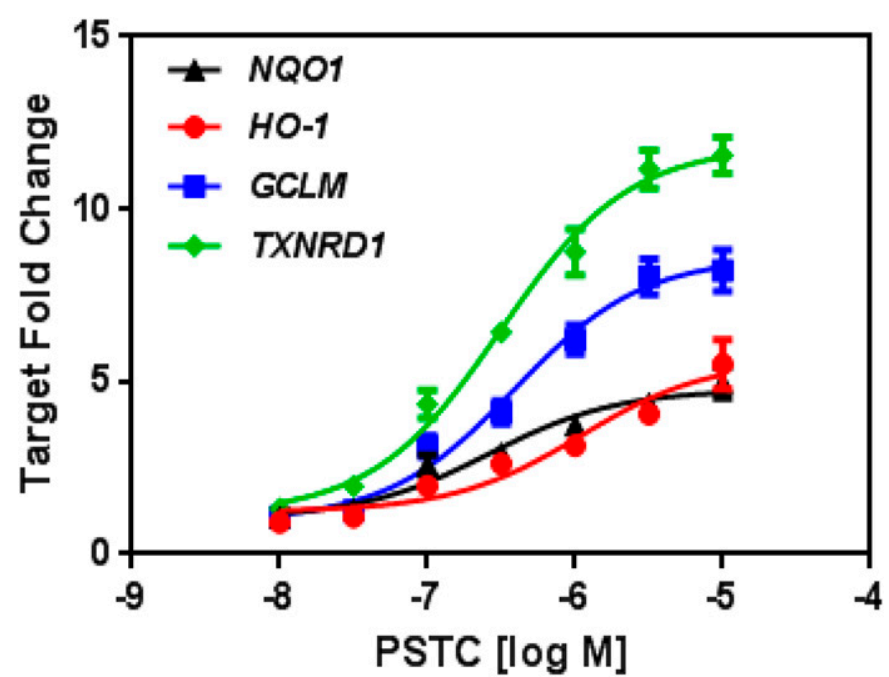

Fig. 6. PSTC induces concentration-dependent expression of Nrf2-regulated genes in a translational COPD model in vitro. Epithelial cells from bronchial brushings of patients with COPD grown in ALI culture were treated with vehicle (DMSO) or PSTC; after 6 hours, NQO1, HO-1, GCLM, and TXNRD1 gene expression was determined. Results of a representative experiment are shown with data expressed as the mean \pm S.E.M. $\operatorname{LogEC} \mathrm{C}_{50}$ values were determined using GraphPad Prism software (version 5.0) with a nonlinear fit and three parameters.

the positive control IKK2 inhibitor (Fig. 5A). In contrast, the Nrf2 activators PSTC and DMF showed little or no inhibition of $\mathrm{NF}-\kappa \mathrm{B}$ translocation at concentrations up to $10 \mu \mathrm{M}$.
To test whether our compound would inhibit mTOR signaling, we used HEK-293 cells stimulated with $100 \mathrm{nM}$ insulin and measured the phosphorylation of $\mathrm{S} 6$ ribosomal protein, a key downstream target of mTOR. When cells were pretreated with SFN $(10 \mu \mathrm{M})$ or CDDO-Me $(1 \mu \mathrm{M})$, the insulin-induced increase in the phospho/total S6 ratio was inhibited (Fig. 5B). This effect was similar to rapamycin (20 nM), a known inhibitor of mTOR signaling. In contrast, PSTC $(10 \mu \mathrm{M})$ and DMF $(30 \mu \mathrm{M})$ had no effect on insulin-induced phospho/total S6 levels. These results suggest that PSTC lacks the NF- $\kappa$ B and mTOR activity previously reported for CDDO-Me (Ahmad et al., 2006; Deeb et al., 2007) and SFN (Xu et al., 2005; Wiczk et al., 2012) and may instead be more specific than these compounds for the Nrf2 pathway.

PSTC Engages Nrf2-Dependent Gene Expression in COPD Patient-Derived Epithelial Cells Maintained in ALI Culture. Published reports suggest that the Nrf2 antioxidant system may be compromised or dysfunctional in patients with COPD (Goven et al., 2008; Yamada et al., 2016). Therefore it is important to evaluate a drug's ability to engage the mechanism in a translational disease setting. For this purpose, we tested the ability of PSTC to engage the Nrf2 pathway via measurement of gene expression by epithelial cells derived from bronchial brushings of patients with COPD. The isolated cells were cultured in an ALI system and treated with the indicated concentrations of PSTC for 6 hours. The compound induced concentration-dependent increases in the gene expression of NQO1, HO-1, GCLM, and TXNRD1, with $\mathrm{pEC}_{50}$ values of $6.6,6.0,6.4$, and 6.5, respectively (Fig. 6). These results demonstrate the ability of PSTC to engage the
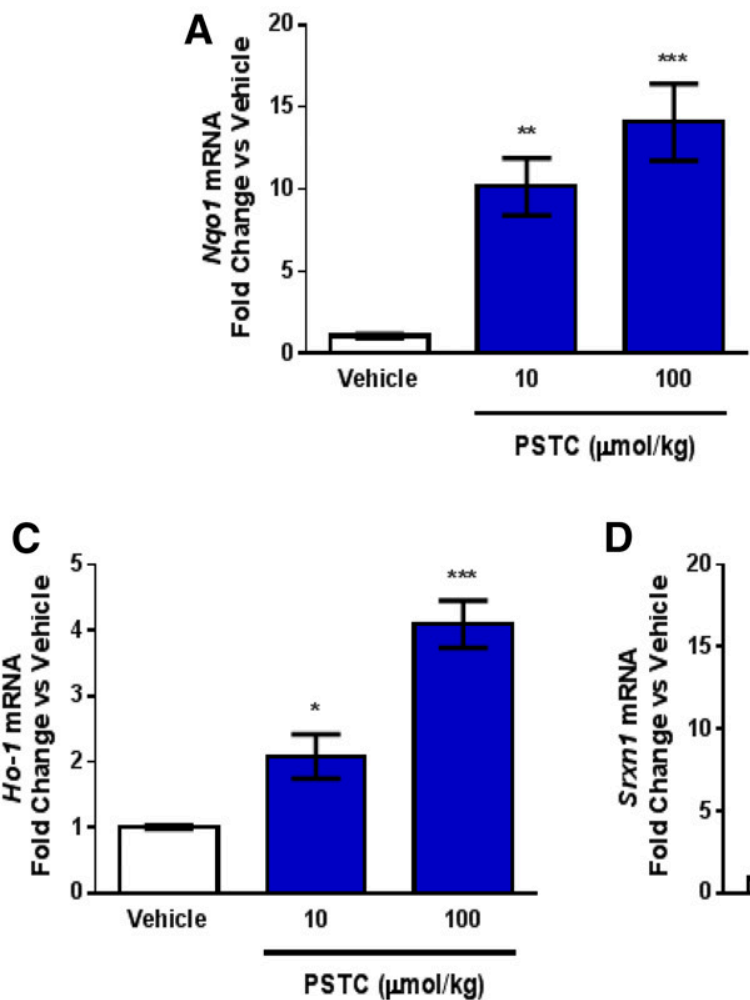

D

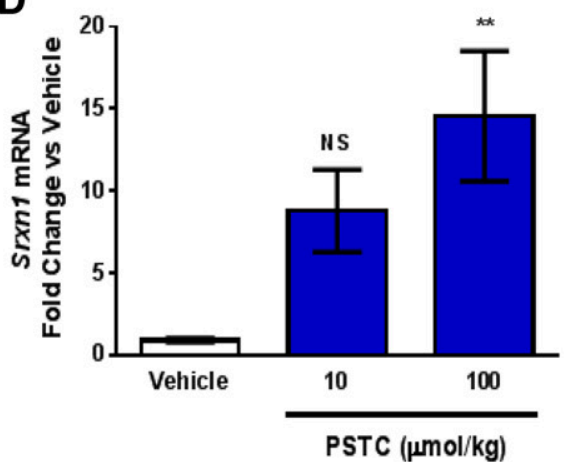

E

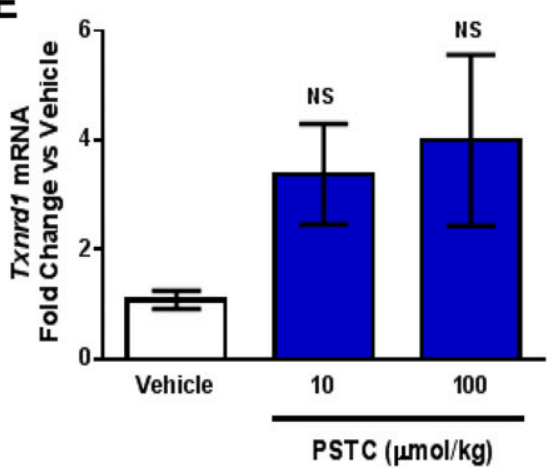

Fig. 7. PSTC induces Nrf2-regulated gene expression and enzyme activity in the lungs of mice. Mice received a single oral administration of vehicle (DMSO, DMA, Cremophor El) or PSTC. (A and C-E) After 6 hours, lung Nqo1 (A), Ho-1 (C), Srxn1 (D), and Txnrd1 (E) gene expression was determined. (B) After 48 hours, lung NQO1 enzyme activity was measured. Data are expressed as the mean \pm S.E.M. $(n=7$ to 8 mice per group). $* P<0.05$; $* * P<0.01 ; * * * P<0.001$. Statistical significance was determined using a one-way analysis of variance with a Dunnett's post-test. NS, not significant versus vehicle-treated mice. 
Nrf2 pathway in human disease-derived cells and provide a translational model for Nrf2 engagement in COPD.

In Vivo Administration of PSTC Induces Nrf2Regulated Gene Expression and Enzyme Activity in the Lungs of Mice. To determine whether the induction of Nrf2-regulated gene expression and enzyme activity demonstrated by PSTC in vitro translates to an in vivo setting, mice received a single administration of compound at 10 or $100 \mu \mathrm{mol} / \mathrm{kg}$ p.o. One hour after compound administration, blood levels of PSTC were $23.9 \pm 2.1$ and $161.3 \pm 26.8 \mathrm{nM}$, respectively, and blood levels of the corresponding hydroxy acid were $395.6 \pm 53.7$ and $2309.9 \pm 494.1 \mathrm{nM}$, respectively. Lung tissue was collected after 6 hours for analysis of mRNA levels and after 48 hours for the analysis of enzyme activity. Compared with vehicle-treated mice, PSTC-treated mice exhibited a dose-dependent increase in Nqo1 gene expression (Fig. 7A), consistent with the dose-dependent increase observed in NQO1 activity (Fig. 7B). Similarly, expression of the Nrf2regulated genes Ho-1, Srxn1, and Txnrd1 increased in a dosedependent manner after administration of PSTC. These results demonstrate engagement of the Nrf2 pathway by PSTC in vivo.

PSTC Inhibits Cigarette Smoke-Induced Pulmonary Inflammation in Mice. To assess the effects of PSTC in an in vivo model of cigarette smoke-induced pulmonary inflammation, mice were administered PSTC at $1,3,10$, or $30 \mu \mathrm{mol} / \mathrm{kg}$ p.o. once daily for 4 consecutive days, concomitant with cigarette smoke exposure on the final 3 days of dosing. One hour after the final compound administration on day 4, blood levels of PSTC were 17.4 $\pm 2.3,37.9 \pm 4.0,63.9 \pm 7.3$, and $142.2 \pm 13.4 \mathrm{nM}$, respectively, and blood levels of the corresponding hydroxy acid were $108.6 \pm 8.9,264.5 \pm 30.6,385.0 \pm 43.2$, and $664.9 \pm 68.7 \mathrm{nM}$, respectively. Six hours after the final compound dose, PSTC (30 $\mu \mathrm{mol} / \mathrm{kg})$-treated/smoke-exposed mice exhibited significantly increased Nqo1, Ho-1, Srxn1, and Txnrd1 gene expression compared with vehicle-treated/ air-exposed mice (Fig. 8). Vehicle-treated/smoke-exposed mice exhibited trends toward increased gene expression, which did not achieve statistical significance, compared with vehicletreated/air-exposed mice. Twenty hours after the final compound dose, vehicle-treated/smoke-exposed mice exhibited significantly increased BAL fluid total cell (Fig. 9A), neutrophil (Fig. 9B), and mononuclear cell (Fig. 9C) numbers and significantly increased lung KC (CXCL1) levels (Fig. 9D), compared with vehicle-treated/air-exposed mice. PSTC inhibited the smoke-induced increase in each cell subset, as well as in KC levels, in a dose-dependent manner. These data indicate that
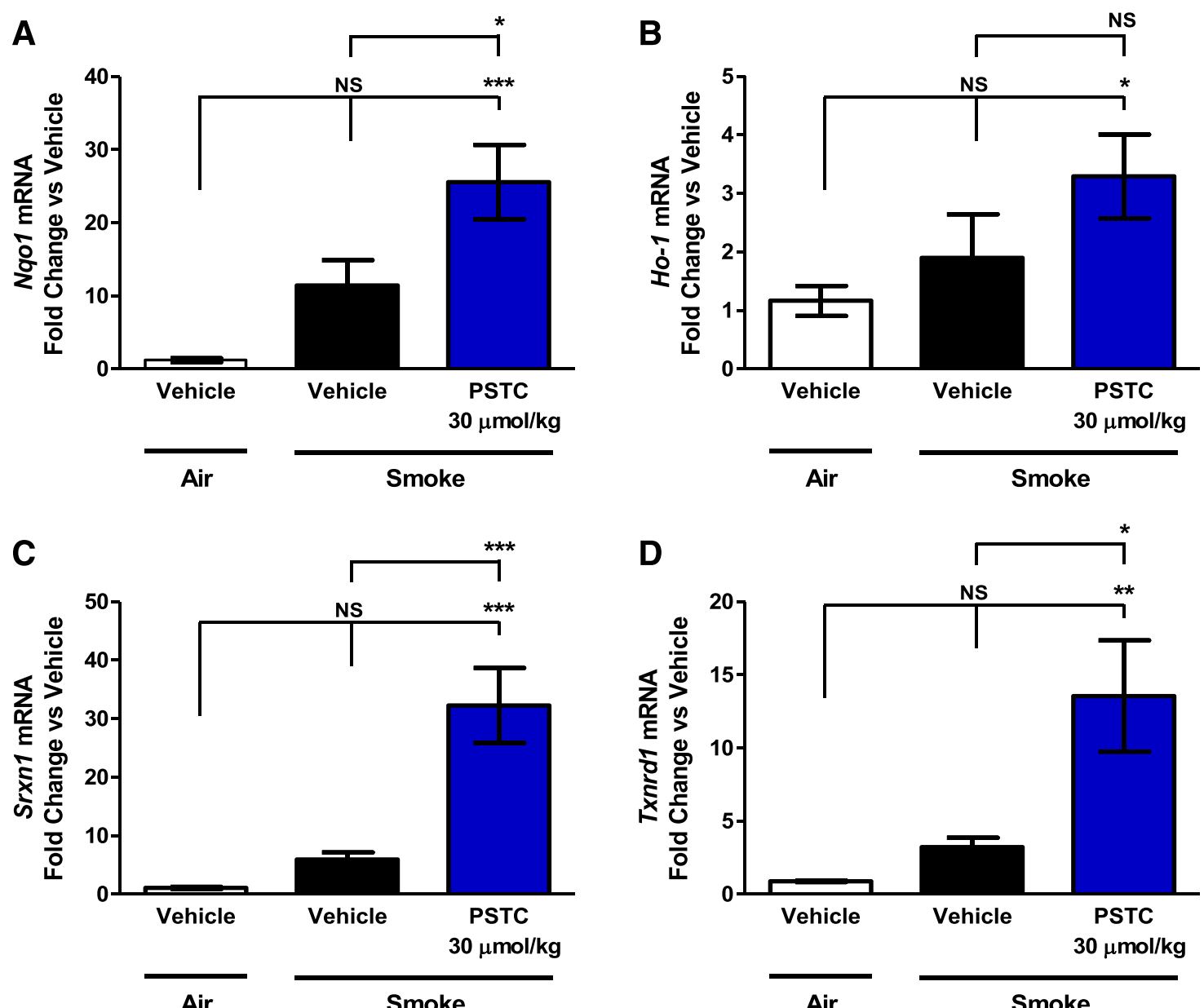

Fig. 8. PSTC induces Nrf2-regulated gene expression in the lungs of cigarette smoke-exposed mice. Mice received daily oral administration of vehicle (DMSO, DMA, Cremophor El) or PSTC during 3 days of smoke exposure as well as 24 hours before the initial smoke exposure. (A-D) Six hours after the final PSTC administration, lung Nqo1 (A), Ho-1 (B), Srxn1 (C), and Txnrd1 (D) gene expression was determined. Data are expressed as the mean \pm S.E.M. ( $n=7$ to 8 mice per group). $* P<0.05 ; * * P<0.01 ; * * * P<0.001$. Statistical significance was determined using a one-way analysis of variance with a Bonferroni post-test. NS, not significant for the comparisons indicated. 
A
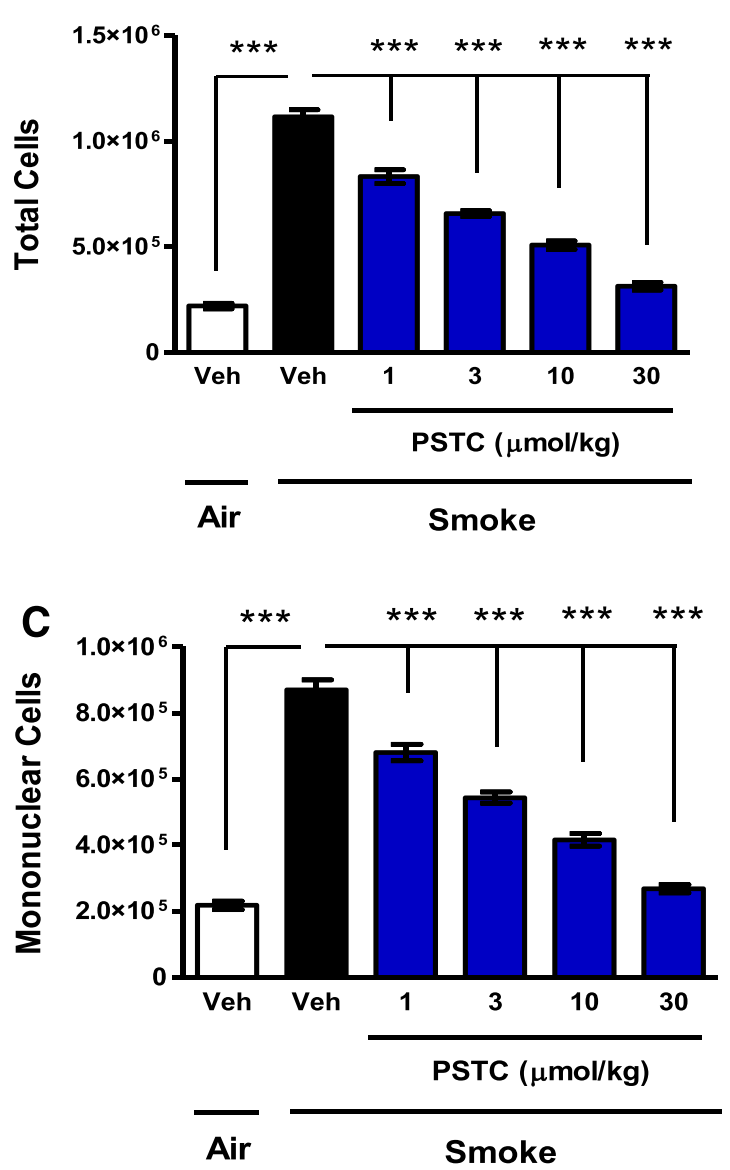
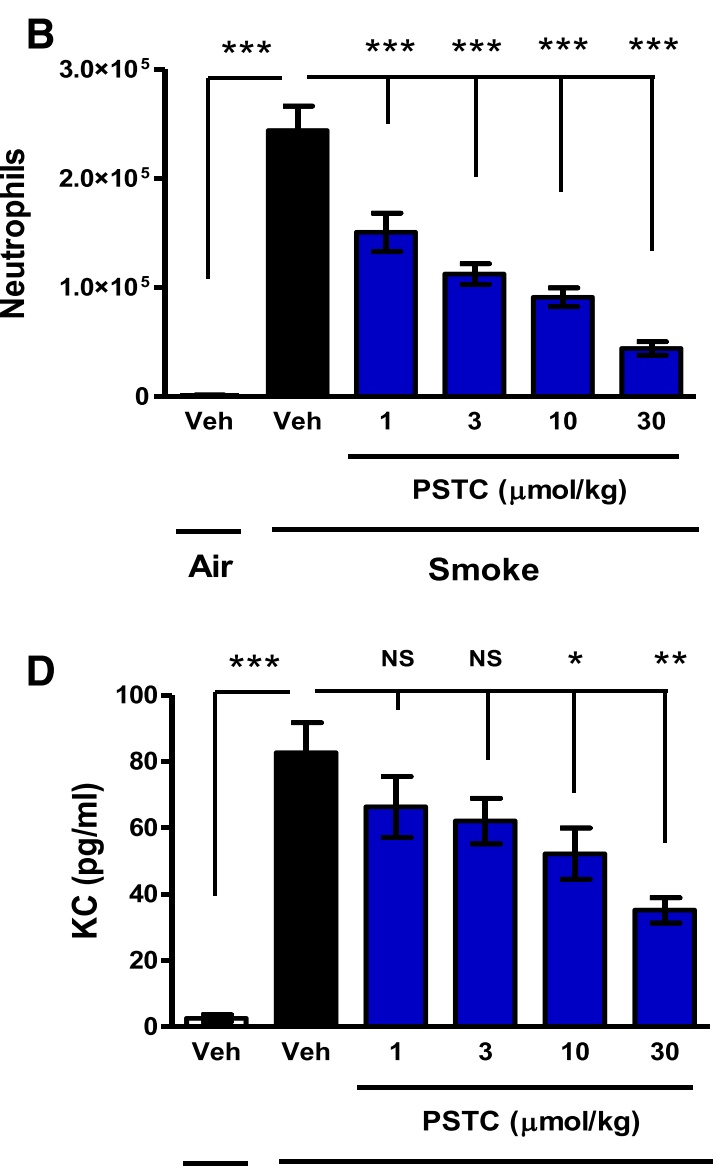

Air

Smoke

Fig. 9. PSTC reduces cigarette smoke-induced pulmonary inflammation in mice. Mice received daily oral administration of vehicle (DMSO, DMA, Cremophor El) or PSTC during 3 days of smoke exposure as well as 24 hours before the initial smoke exposure. (A-D) Twenty hours after the final PSTC administration, BAL fluid total cell (A), neutrophil (B), and mononuclear cell (C) numbers were determined, and lung KC (D) levels were measured. Data are expressed as the mean \pm S.E.M. ( $n=7$ to 8 mice per group). ${ }^{*} P<0.05 ; * * P<0.01 ; * * * P<0.001$. Statistical significance was determined using a oneway analysis of variance with a Dunnett's post-test. NS, not significant for the comparisons indicated.

PSTC attenuates cigarette smoke-induced pulmonary inflammation in vivo.

In Vivo Administration of PSTC Induces Nrf2Regulated Gene Expression and Enzyme Activity in the Lungs of Rats. Rats received a single administration of compound at 3 or $10 \mu \mathrm{mol} / \mathrm{kg}$ p.o. One hour after compound administration, blood levels of PSTC were $30.3 \pm 4.2$ and $88.0 \pm 14.6 \mathrm{nM}$, respectively, and blood levels of the corresponding hydroxy acid were $699.4 \pm 94.2$ and $2035.0 \pm 362.3 \mathrm{nM}$, respectively. Similar to the results observed in the lungs of mice, rats exhibited a dose-dependent increase in Nqo1 gene expression at 6 hours postdose (Fig. 10A), followed by a dosedependent increase in NQO1 activity at 48 hours postdose (Fig. 10B). The dose-dependent increases observed in Ho-1 (Fig. 10C), Srxn1 (Fig. 10D), and Txnrd1 (Fig. 10E) gene expression further support the conclusion that in vivo administration of PSTC results in engagement of the Nrf2 pathway in rats.

PSTC Inhibits Ozone-Induced Pulmonary Inflammation and Restores Lung Glutathione Levels in Rats. In a second model of oxidative stress/pulmonary inflammation, treatment of rats with PSTC $(10 \mu \mathrm{mol} / \mathrm{kg}) 24$ hours prior to ozone exposure resulted in, at 15 minutes postozone exposure, significant inhibition of the ozone-induced increases in BAL fluid total cell (Fig. 11A), neutrophil (Fig. 11B), and mononuclear cell (Fig. 11C) numbers and in significant restoration of the ozone-induced depletion of lung glutathione levels (Fig. 11D). These results indicate that PSTC attenuates both the pulmonary inflammation and glutathione depletion induced by ozone in the rat.

\section{Discussion}

Development of new therapies to address unmet needs, especially those that can slow disease progression in COPD, is of utmost importance to patients and clinicians (Patalano et al., 2014). Oxidative stress plays an important role in COPD and thus has garnered attention as a potential area for new therapies. Several aspects of COPD are associated with an impaired response to oxidative stress, including potential generation of damage-associated molecular pattern molecules from chronic cigarette smoke exposure (Guo et al., 2008), suppression of histone deacetylase 2 activity, which can amplify inflammatory responses (Osoata et al., 2009) and lead to corticosteroid resistance (Ito et al., 2006), and disruption of innate immune defenses associated with acute exacerbations (Berenson et al., 2006). More specifically, evidence has suggested that the master redox regulator Nrf2 is defective 


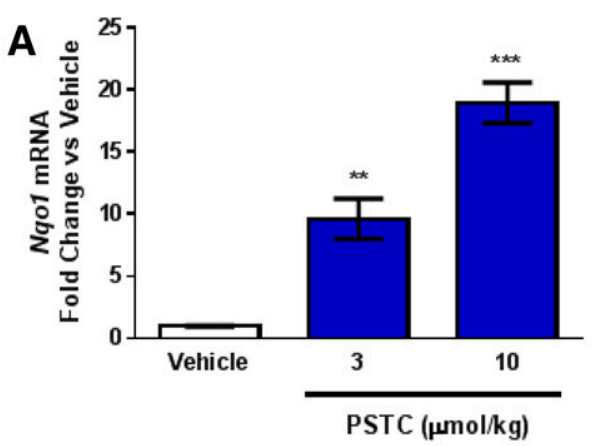

C

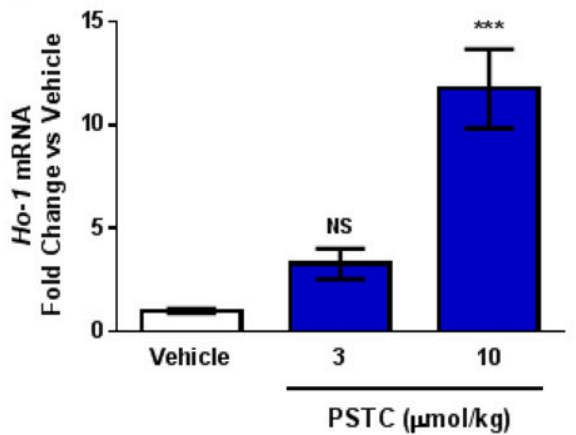

D

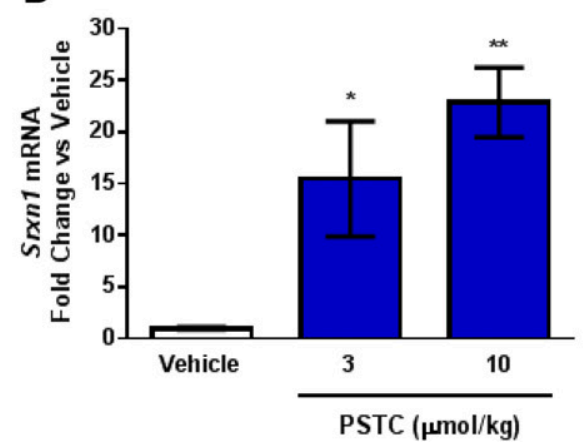

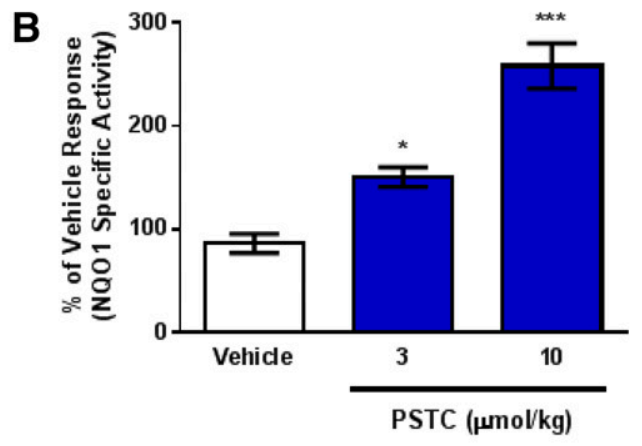

E

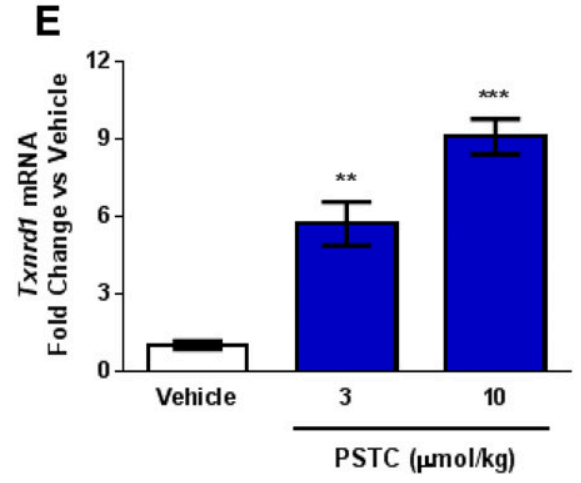

Fig. 10. PSTC induces Nrf2-regulated gene expression and enzyme activity in the lungs of rats. Rats received a single oral administration of vehicle (DMSO, DMA, Cremophor El) or PSTC. (A and C-E) After 6 hours, lung Nqo1 (A), Ho-1 (C), Srxn1 (D), and Txnrd1 (E) gene expression was determined. (B) After 48 hours, lung NQO1 enzyme activity was measured. Data are expressed as the mean \pm S.E.M. $(n=5$ rats per group). $* P<0.05$; $* * P<0.01$; *** $P<0.001$. Statistical significance was determined using a one-way analysis of variance with a Dunnett's post-test. NS, not significant versus vehicletreated rats.

in COPD (Hillas et al., 2013); thus, targeting activation of Nrf2 via repression of Keap1 could rebalance oxidative stress and could be an effective treatment of some aspects of COPD. Here we investigated the ability of our compound to activate Nrf2 and demonstrate protection in various cellular and animal models of pulmonary oxidative stress.

In NHBE cells, PSTC induced Nrf2 nuclear translocation and the subsequent expression of phase II antioxidant genes and enzymes such as HO-1 and NQO1 in an Nrf2-dependent manner. A functional outcome of this target engagement was the concentration-dependent restoration of oxidant (tBHP)induced glutathione depletion in these cells. Similarly, in vivo administration of PSTC to mice and rats induced the dosedependent pulmonary expression of Nrf2-regulated genes and NQO1 activity and restored oxidant (ozone)-induced depletion of lung glutathione levels. Consistent with these results, the regulation of glutathione content by Nrf2 has previously been demonstrated in both human cell systems and rodent in vivo models (Thimmulappa et al., 2006; Kode et al., 2008). Furthermore, the Nrf2 activators CDDO-Me, SFN, and DMF have been shown to modify glutathione levels (Tarozzi et al., 2009; Reisman et al., 2012; Brennan et al., 2015). Maintenance of glutathione homeostasis is critical, as glutathione is the major endogenous nonprotein thiol in cells and plays a key role in redox status (Forman and Dickinson, 2003). Moreover, glutathione is important in the lung, defending the airways from damage in response to oxidants and inflammation (Biswas and Rahman, 2009).

A key factor in drug discovery is the ability to demonstrate that compound activity in normal cells and naive animals translates into efficacy in disease models. As previously noted,
Nrf2 signaling has been reported to be defective in patients with COPD (Goven et al., 2008; Yamada et al., 2016); therefore, it is important to determine whether PSTC activates Nrf2 in disease cells. In an ALI culture model of epithelial cells from bronchial brushings of patients with COPD, the compound was able to engage the Nrf2 pathway, inducing the expression of multiple Nrf2-regulated genes in a concentration-dependent manner. Similarly, in an acute cigarette smoke exposure model, PSTC increased Nrf2regulated gene expression in the lungs of mice. This engagement of the target in challenged mice was followed by dose-dependent inhibition of leukocyte influx into the BAL fluid. Likewise, in an ozone model of pulmonary oxidative stress, PSTC decreased BAL fluid leukocyte numbers in rats. The anti-inflammatory effects exhibited by this Nrf2 activator are consistent with the elevated leukocyte numbers observed in the BAL fluid of cigarette smoke-exposed Nrf2 gene-deficient mice, compared with wild-type control mice (Rangasamy et al., 2004). Collectively, in both in vitro and in vivo disease systems, PSTC demonstrated target engagement, anti-inflammatory effects, and the reversal of glutathione depletion, suggesting its potential efficacy in the treatment of COPD.

A primary goal of the work described herein was to develop a potent and selective activator of Nrf2. In the NQO1 enzyme activity assay in BEAS-2B cells, the potency exhibited by PSTC was markedly increased compared with SFN and DMF and was within a log of the potency exhibited by CDDO-Me. With regard to selectivity, both CDDO-Me (Ahmad et al., 2006) and SFN (Xu et al., 2005) have been reported to inhibit $\mathrm{NF}-\kappa \mathrm{B}$ signaling and indeed attenuated NF- $\kappa \mathrm{B}$ translocation 
A

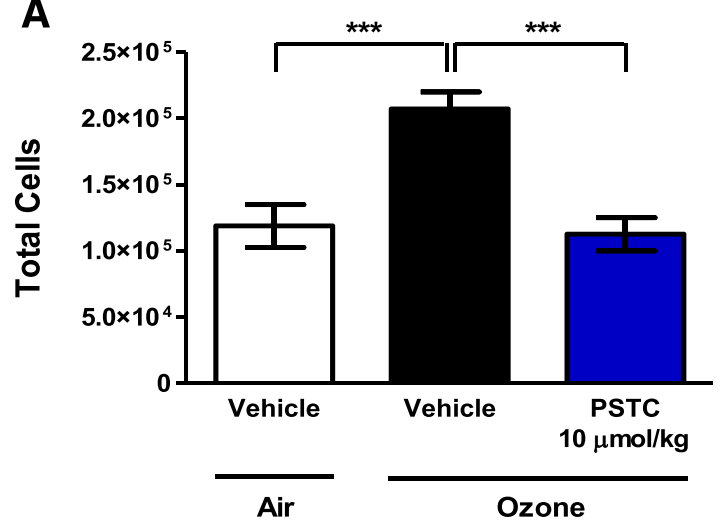

C

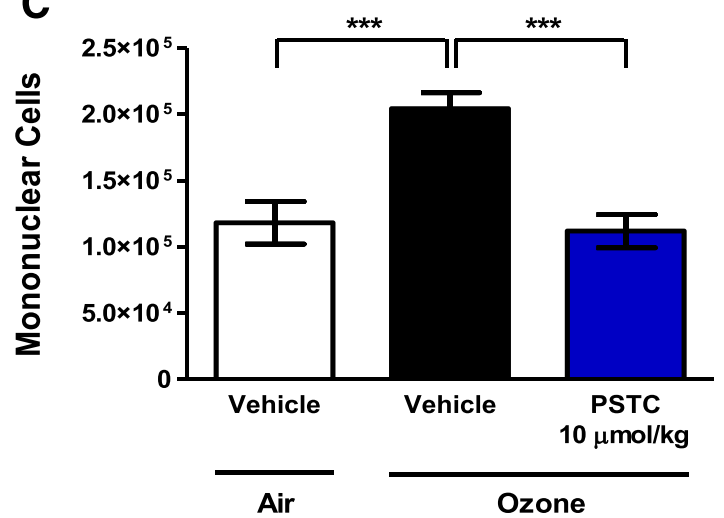

B

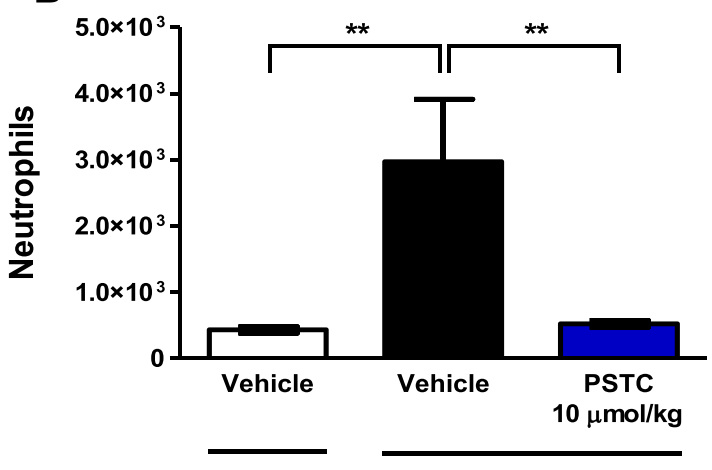

Air

D

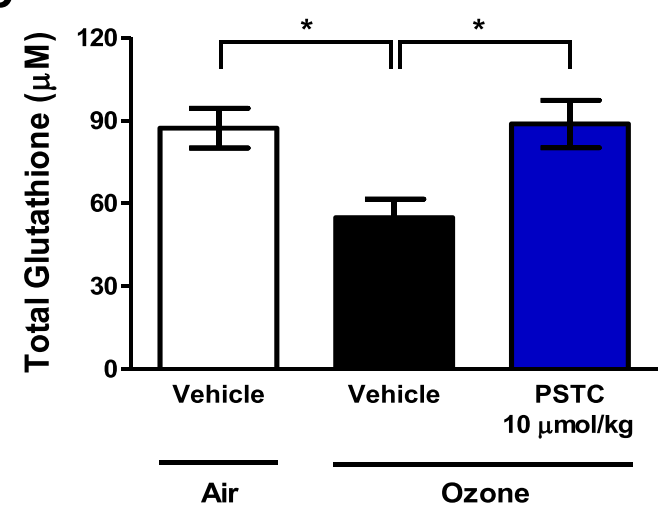

Fig. 11. PSTC reduces pulmonary inflammation and restores lung glutathione levels in ozone-exposed rats. Rats received a single oral administration of vehicle (DMSO, DMA, Cremophor El) or PSTC 24 hours prior to ozone exposure. (A-D) Fifteen minutes after ozone exposure, BAL fluid total cell (A), neutrophil (B), and mononuclear cell (C) numbers were determined and lung glutathione (D) levels were measured. Data are expressed as the mean \pm S.E.M. ( $n=7-9$ rats per group). $* P<0.05 ; * * P<0.01 ; * * * P<0.001$. Statistical significance was determined using a one-way analysis of variance with a Dunnett's post-test. NS, not significant for the comparisons indicated.

in NHBE cells, whereas PSTC and DMF demonstrated little or no inhibition in this assay. Similarly, in an assay to detect inhibition of mTOR signaling, CDDO-Me and SFN (but not PSTC or DMF) demonstrated activity, consistent with published reports (Deeb et al., 2007; Wiczk et al., 2012). Furthermore, in a selectivity panel containing 50 enzymes, receptors, ion channels, and phenotypic cell health screens, CDDO-Me exhibited activity against 19 targets, whereas PSTC and SFN were each active against a single target and DMF was inactive. Collectively, these results indicate that PSTC exhibits relatively comparable potency but greater selectivity than CDDO-Me, increased potency and selectivity compared with SFN, and increased potency but marginally less selectivity than DMF.

In summary, we have demonstrated that PSTC is a potent and selective activator of the Nrf2 signaling pathway, inducing expression of Nrf2-regulated genes and proteins in normal human pulmonary cells and in the lungs of naive rodents, as well as in human disease cells and in vivo models of pulmonary disease. A functional marker of this target engagement was the compound's reversal of oxidant-induced glutathione depletion in both cell-based and whole animal systems. In addition, PSTC inhibited cigarette smoke- and ozone-induced pulmonary inflammation in rodents. These results suggest that PSTC has therapeutic potential in diseases driven by oxidative stress and inflammation, such as COPD.

\section{Acknowledgments}

We thank Dr. Steven Kelsen and colleagues and the donors who provided lung samples to support these studies.

\section{Authorship Contributions}

Participated in research design: Yonchuk, Foley, Bolognese, Logan, Wixted, Kou, Chalupowicz, Feldser, Sanchez, Nie, Callahan, Kerns, Podolin.

Conducted experiments: Yonchuk, Foley, Bolognese, Logan, Wixted, Kou, Chalupowicz, Nie.

Contributed new reagents or analytic tools: Nie, Callahan, Kerns.

Performed data analysis: Yonchuk, Foley, Bolognese, Logan, Wixted, Kou, Chalupowicz, Feldser, Sanchez, Nie, Callahan, Kerns, Podolin.

Wrote or contributed to the writing of the manuscript: Yonchuk, Foley, Bolognese, Chalupowicz, Feldser, Sanchez, Callahan, Kerns, Podolin.

\section{References}

Ahmad R, Raina D, Meyer C, Kharbanda S, and Kufe D (2006) Triterpenoid CDDO-Me blocks the NF-kappaB pathway by direct inhibition of IKKbeta on Cys-179. $J$ Biol Chem 281:35764-35769.

Baird L and Dinkova-Kostova AT (2011) The cytoprotective role of the Keap1-Nrf2 pathway. Arch Toxicol 85:241-272.

Barnes PJ (2014) Cellular and molecular mechanisms of chronic obstructive pulmonary disease. Clin Chest Med 35:71-86.

Berenson CS, Garlipp MA, Grove LJ, Maloney J, and Sethi S (2006) Impaired phagocytosis of nontypeable Haemophilus influenzae by human alveolar macrophages in chronic obstructive pulmonary disease. J Infect Dis 194:1375-1384.

Biswas SK and Rahman I (2009) Environmental toxicity, redox signaling and lung inflammation: the role of glutathione. Mol Aspects Med 30:60-76.

Brennan MS, Matos MF, Li B, Hronowski X, Gao B, Juhasz P, Rhodes KJ, and Scannevin RH (2015) Dimethyl fumarate and monoethyl fumarate exhibit 
differential effects on KEAP1, NRF2 activation, and glutathione depletion in vitro. PLoS One 10: 0120254.

Chen H, Assmann JC, Krenz A, Rahman M, Grimm M, Karsten CM, Köhl J, Offermanns S, Wettschureck N, and Schwaninger M (2014) Hydroxycarboxylic acid receptor 2 mediates dimethyl fumarate's protective effect in EAE. J Clin Invest 124:2188-2192.

Chin MP, Reisman SA, Bakris GL, O'Grady M, Linde PG, McCullough PA, Packham D, Vaziri ND, Ward KW, Warnock DG, et al. (2014) Mechanisms contributing to adverse cardiovascular events in patients with type 2 diabetes mellitus and stage 4 chronic kidney disease treated with bardoxolone methyl. Am J Nephrol $\mathbf{3 9}$ 499-508.

Cleasby A, Yon J, Day PJ, Richardson C, Tickle IJ, Williams PA, Callahan JF, Carr R, Concha N, Kerns JK, et al. (2014) Structure of the BTB domain of Keap1 and its interaction with the triterpenoid antagonist CDDO. PLoS One 9:e98896.

Davies TG, Wixted WE, Coyle JE, Griffiths-Jones C, Hearn K, McMenamin R, Norton D, Rich SJ, Richardson C, Saxty G, et al. (2016) Monoacidic inhibitors of the Kelchlike ECH-associated protein 1: nuclear factor erythroid 2-related factor 2 (KEAP1: NRF2) protein-protein interaction with high cell potency identified by fragmentbased discovery. J Med Chem 59:3991-4006.

de Zeeuw D, Akizawa T, Audhya P, Bakris GL, Chin M, Christ-Schmidt H, Goldsberry A, Houser M, Krauth M, Lambers Heerspink HJ, et al.; BEACON Trial Investigators (2013) Bardoxolone methyl in type 2 diabetes and stage 4 chronic kidney disease. N Engl J Med 369:2492-2503.

Deeb D, Gao X, Dulchavsky SA, and Gautam SC (2007) CDDO-Me induces apoptosis and inhibits Akt, mTOR and NF-kappaB signaling proteins in prostate cancer cells. Anticancer Res 27:3035-3044.

Forman HJ and Dickinson DA (2003) Oxidative signaling and glutathione synthesis. Biofactors 17:1-12.

Goven D, Boutten A, Leçon-Malas V, Marchal-Sommé J, Amara N, Crestani B, Fournier M, Lesèche G, Soler P, Boczkowski J, et al. (2008) Altered Nrf2/Keap1 Bach1 equilibrium in pulmonary emphysema. Thorax 63:916-924.

Guo C-J, Atochina-Vasserman EN, Abramova E, Foley JP, Zaman A, Crouch E, Beers MF, Savani RC, and Gow AJ (2008) S-nitrosylation of surfactant protein-D controls inflammatory function. PLoS Biol 6:e266.

Hillas G, Nikolakopoulou S, Hussain S, and Vassilakopoulos T (2013) Antioxidants and mucolytics in COPD management: when (if ever) and in whom? Curr Drug Targets 14:225-234.

Ito K, Yamamura S, Essilfie-Quaye S, Cosio B, Ito M, Barnes PJ, and Adcock IM (2006) Histone deacetylase 2-mediated deacetylation of the glucocorticoid receptor enables NF-kappaB suppression. J Exp Med 203:7-13.

Itoh K, Chiba T, Takahashi S, Ishii T, Igarashi K, Katoh Y, Oyake T, Hayashi N, Satoh K, Hatayama I, et al. (1997) An Nrf2/small Maf heterodimer mediates the induction of phase II detoxifying enzyme genes through antioxidant response elements. Biochem Biophys Res Commun 236:313-322.

Itoh K, Wakabayashi N, Katoh Y, Ishii T, Igarashi K, Engel JD, and Yamamoto M (1999) Keap1 represses nuclear activation of antioxidant responsive elements by Nrf2 through binding to the amino-terminal Neh2 domain. Genes Dev 13: 76-86.

Kode A, Rajendrasozhan S, Caito S, Yang S-R, Megson IL, and Rahman I (2008) Resveratrol induces glutathione synthesis by activation of Nrf2 and protects against cigarette smoke-mediated oxidative stress in human lung epithelial cells. Am J Physiol Lung Cell Mol Physiol 294:L478-L488.
Motohashi H, O'Connor T, Katsuoka F, Engel JD, and Yamamoto M (2002) Integration and diversity of the regulatory network composed of Maf and CNC families of transcription factors. Gene 294:1-12.

Osoata GO, Yamamura S, Ito M, Vuppusetty C, Adcock IM, Barnes PJ, and Ito K (2009) Nitration of distinct tyrosine residues causes inactivation of histone deacetylase 2. Biochem Biophys Res Commun 384:366-371.

Patalano F, Banerji D, D'Andrea P, Fogel R, Altman P, and Colthorpe P (2014) Addressing unmet needs in the treatment of COPD. Eur Respir Rev 23:333-344. Phillips JT and Fox RJ (2013) BG-12 in multiple sclerosis. Semin Neurol 33:56-65. Podolin PL, Callahan JF, Bolognese BJ, Li YH, Carlson K, Davis TG, Mellor GW, Evans C, and Roshak AK (2005) Attenuation of murine collagen-induced arthritis by a novel, potent, selective small molecule inhibitor of IkappaB kinase 2, TPCA-1 (2-[(aminocarbonyl)amino]-5-(4-fluorophenyl)-3-thiophenecarboxamide), occurs via reduction of proinflammatory cytokines and antigen-induced T cell proliferation. $J$ Pharmacol Exp Ther 312:373-381.

Prochaska HJ and Santamaria AB (1988) Direct measurement of NAD(P)H:quinone reductase from cells cultured in microtiter wells: a screening assay for anticarcinogenic enzyme inducers. Anal Biochem 169:328-336.

Rangasamy T, Cho CY, Thimmulappa RK, Zhen L, Srisuma SS, Kensler TW, Yamamoto M, Petrache I, Tuder RM, and Biswal S (2004) Genetic ablation of Nrf2 enhances susceptibility to cigarette smoke-induced emphysema in mice. $J$ Clin Invest 114:1248-1259.

Reisman SA, Chertow GM, Hebbar S, Vaziri ND, Ward KW, and Meyer CJ (2012) Bardoxolone methyl decreases megalin and activates Nrf2 in the kidney. J Am Soc Nephrol 23:1663-1673.

Rojas-Rivera J, Ortiz A, and Egido J (2012) Antioxidants in kidney diseases: the impact of bardoxolone methyl. Int $J$ Nephrol 2012:321714.

Ross SJ and Critchlow SE (2014) Emerging approaches to target tumor metabolism. Curr Opin Pharmacol 17:22-29.

Tarozzi A, Morroni F, Merlicco A, Hrelia S, Angeloni C, Cantelli-Forti G, and Hrelia P (2009) Sulforaphane as an inducer of glutathione prevents oxidative stress-induced cell death in a dopaminergic-like neuroblastoma cell line. J Neurochem 111: 1161-1171.

Thimmulappa RK, Lee H, Rangasamy T, Reddy SP, Yamamoto M, Kensler TW, and Biswal S (2006) Nrf2 is a critical regulator of the innate immune response and survival during experimental sepsis. J Clin Invest 116:984-995.

Wiczk A, Hofman D, Konopa G, and Herman-Antosiewicz A (2012) Sulforaphane, a cruciferous vegetable-derived isothiocyanate, inhibits protein synthesis in human prostate cancer cells. Biochim Biophys Acta 1823:1295-1305.

Xu C, Shen G, Chen C, Gélinas C, and Kong A-NT (2005) Suppression of NF-kappaB and NF-kappaB-regulated gene expression by sulforaphane and PEITC through IkappaBalpha, IKK pathway in human prostate cancer PC-3 cells. Oncogene 24:4486-4495.

Yamada K, Asai K, Nagayasu F, Sato K, Ijiri N, Yoshii N, Imahashi Y, Watanabe T, Tochino Y, Kanazawa H, et al. (2016) Impaired nuclear factor erythroid 2-related factor 2 expression increases apoptosis of airway epithelial cells in patients with chronic obstructive pulmonary disease due to cigarette smoking. BMC Pulm Med 16:27.

Address correspondence to: Dr. Patricia L. Podolin, GlaxoSmithKline, Mail Code UW2532, 709 Swedeland Rd., King of Prussia, PA 19406. E-mail: patty. podolin@gsk.com 